\title{
Nehirlerde Mikroplastik Kirliliği ve Hidrodinamik Modellenmesi
}

\author{
Olcay Gülçiçek Uysal 1*, \\ 1*Mersin Üniversitesi, Mühendislik Fakültesi, Çevre Mühendisliği Bölümü, Mersin, Türkiye, (ORCID: 0000-0001-9032-4241), olcayozer@mersin.edu.tr
}

(1st International Conference on Applied Engineering and Natural Sciences ICAENS 2021, November 1-3, 2021)

(DOI: 10.31590/ejosat.1015595)

ATIF/REFERENCE: Gülçiçek Uysal, O. (2021). Nehirlerde Mikroplastik Kirliliği ve Hidrodinamik Modellenmesi. Avrupa Bilim ve Teknoloji Dergisi, (28), 1410-1414.

$\ddot{O} \mathbf{z}$

Plastik atıklar, günümüzün en önemli çevresel sorunlarından biri olarak kabul edilmiştir. Bu atıkların kaynaklarının çoğu karasal olduğundan, çalışmalarda tatlı su ve karasal çevreye odaklanılmaktadır. Tatlı su kaynaklarından nehirler ise, denizlere ve okyanuslara mikroplastik taşıyan en önemli kaynaktır. Bu nedenle, nehirlerde mikroplastik kirliliğinin anlaşılabilmesi önemlidir. Bu derleme çalışmada mikroplastikler ve ekosistemlere giriş yolları, nehirlerde mikroplastiklerin akıbeti ve taşınımı ile ilgili yapılan hidrodinamik modellerin öncü çalışmaları incelenmiştir. Mikroplastiklerin nehirlerde taşınımında zamana ve mekana bağlı değişimi tartışılmıştır.

Anahtar Kelimeler: Mikroplastik, Nehir, Modelleme.

\section{Microplastic Pollution and Hydrodynamic Modeling in Rivers}

\begin{abstract}
Plastic waste has been recognized as one of the most important environmental problems of today. Since most of the sources of these wastes are terrestrial, studies focus on fresh water and terrestrial environment. Rivers, which are one of the fresh water resources, are the most important source of microplastics to the seas and oceans. Therefore, it is important to be able to understand microplastic pollution in rivers. In this review, pioneering studies of hydrodynamic models on microplastics and their entry routes into ecosystems, fate and transport of microplastics in rivers are examined. The temporal and spatial variation of the transport of microplastics in rivers is discussed.
\end{abstract}

Keywords: Microplastic, River, Modelling.

\footnotetext{
* Sorumlu Yazar: olcayozer@mersin.edu.tr
} 


\section{Giriş}

Günümüz dünyasının en önemli kullanım araçlarından biri olan plastiklerin üretimi her geçen yılla birlikte rekor düzeylere ulaşmakta ve gelecek trendler dikkate alındığında da bu artışın hız kesmeden devam edeceği öngörülmektedir [1].

Plastikler fosil kaynaklardan ya da selüloz vb. organik ürünlerden türetilen, çeşitli monomerlerin uzun zincirli yapılara dönüştürülmesiyle elde edilen sentetik ve yarı sentetik materyallerdir ve önemli kullanım araçlarındandır [2].

Hava, su ve toprak ortamında çeşitli modelleme çalışmaları yapılarak, atık ve artıkların yayılımı, alıcı ortamın çevresel kalitesi ve bu kaliteyi oluşturan tüm fiziksel, kimyasal, biyokimyasal ve ekolojik süreç ve mekanizmalar üzerine etkisi hakkında tahminler ve senaryolar üretilmektedir. Yapılan çalışmalarda plastik atıkların su ortamındaki miktarı ve akıbeti üzerine veri elde edilmesindeki zorlukların, var olan kirletici taşınım modellerinin plastiklere modifiye edilmesi ile geliştirilebileceği ortaya konulmuştur [3,4,5].

Bu çalışma ile mikroplastiklerin özellikleri, kaynakları, nehir sistemlerinde taşınımı ve akıbeti ile ilgili hidrodinamik modeller ile elde edilen sonuçlar değerlendirilerek mikroplastiklerin nehirler üzerindeki zararlı etkilerinin azaltılmasına yönelik yol haritasının ortaya konulmasına katkı sağlamak amaçlanmıştır.

\section{Plastik ve Mikroplastikler}

Çeşitli polimer tiplerine ve yoğunluğa sahip bu materyaller ya birtakım amaçlarla oldukça küçük boyutlarda üretilmekte (primer mikroplastikler) ya da büyük plastik enkazın mikrobiyal degredasyon, UV ışınları, asidite, turbasyon vb. mekanizmalarla su ortamında daha küçük boyutlara (sekonder mikroplastikler) parçalanmasıyla meydana gelmektedir [2]. Boyutları $1 \mu \mathrm{m}-5 \mathrm{~mm}$ arasında değişen plastikler mikroplastik olarak tanımlanmaktadır. $\mathrm{Su}$ kolonundan sedimente değin çevrede birikim gösteren bu partiküller başta sucul ekosistemlerde olmak üzere biyota ile çeşitli şekillerde etkileşime girerek canlılar için büyük tehdit içermekte ve önemli bir risk durumu doğurmaktadır.

Mikroplastik terimini Thompson ve arkadaşları [6] genel olarak 5 mm' den küçük olan plastik parçacıklar olarak ilk tanımlayanlardır. Mikroplastikler boyutlarına göre küçük ve büyük mikroplastikler olarak iki grupta ele alınmış olup [7], parçacık boyutları için nano, mikro, mezo ve makro olarak yapılan sınıflandırma Şekil 1 de gösterilmektedir [8].

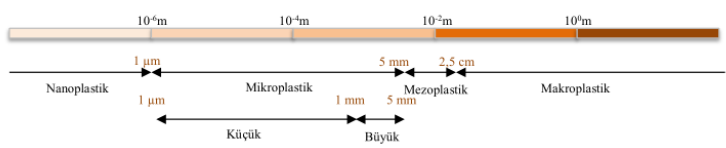

Şekil 1. Plastik parçalarının boyutlarının tanımlanması [8].

Plastikler bulundukları ortamda birçok prosese maruz kalarak boyutsal ve şekilsel olarak değişirler (UV 1şınları, sıcaklık, asidite, turbasyon, mikrobiyal degredasyon) [9]. Mikroplastik kirliliği büyük plastik atıkların yukarda bahsedilen prosesler ile daha küçük boyutlara parçalanması (ikincil mikroplastikler) ya da birtakım amaçlar için üretilen mikron boyutlardaki plastiklerin (birincil mikroplastikler) çevresel kompartımanlara girmesiyle meydana gelir.
Birincil mikroplastik kaynaklarını oluşturan malzemelerin yüz bakım ürünlerinden duş jellerine, diş macunlarından makyaj malzemelerine, boya sanayiden medikal ürünlere kadar geniş bir kullanım yelpazesi vardır [10]. İkincil mikroplastik kaynakları ise hem denizde hem de karada daha büyük plastik döküntülerin parçalanmasından elde edilen, sentetik giysilerden kaynaklanan mikrofibriller ve sentetik lastik yapıların (road dust) aşınmasıdır $[11,12]$

Yoğunluklarına bağlı olarak mikroplastikler su ortamında batma ya da yüzme eğilimi göstermektedirler. Plastik malzemelerin \%46'sı normal şartlarda yüzme eğilimindedir [13]. Yine de plastiklerin yüzeyinde meydana gelen mikrobiyal kolonizasyon, biyofilm oluşumu gibi faktörler bu partiküllerin yoğunluğunu arttırarak su kolonu boyunca batmasına neden olmaktadir [14].

\section{Mikroplastiklerin Ekosistemlere Giriş Kaynakları}

Su kirliliğinin nispeten yeni fark edilen bir boyutu da plastik kirliliğidir. Denizlere ve nihayetinde okyanuslara karışan plastiklerin çoğu karadan gelen büyük plastiklerden kaynaklanmaktadır. Büyük plastik parçalar; rüzgârlar, dalgalar, ultraviyole 1şınlarının etkisiyle mikroplastiklere bölünerek nehirler ile göllere ve denizlere ulaşmaktadır [15].

Kişisel bakım, temizlik ürünlerine üretim aşamasında küçük boyutlu mikroplastikler ilave edilmektedir. Sentetik lifler formunda olanlar ise tekstil endüstrisinde kullanılmaktadır [16, 15]. Bahsedilen bu ürünlerin her evde sıklıkla kullanıldığını varsayarsak ürünlerdeki mikroplastikler öncelikle kanalizasyon sistemine ve daha sonra atıksu arıtma tesislerinde aritılamazsa doğrudan su kaynaklarına ulaşmaktadır. Ülkemizde su kaynaklarında yapılan mikroplastik kirliliği araştırmaları sonucuna göre, en büyük kaynağın atık su arıtma tesisleri olduğunu ortaya koymuştur [17]. Birçok ileri arıtma yönteminin mikroplastik gideriminde etkili olduğu artık biliniyor olsada mikroplastiklerin arıtımı ile ilgili yasal bir zorunluluk bulunmadığından arıtma tesisleri mikroplastik giderimi maksatlı dizayn edilmemiştir.

Örneğin, Kuzey Denizi'ne giren Avrupa'nın en büyük nehirlerinden biri olan Ren Nehri boyunca mikroplastik konsantrasyonları, nehrin gelgit bölgesi dışında mansap yönünde önemli ölçüde artmaktadır [18]. Chesapeake Körfezi'ne giren dört nehir ağzı nehrindeki mikroplastik konsantrasyonlarının nüfus yoğunluğuna ve arazi kullanımına bağlı olduğu bulundu [19].

Son zamanlarda, nehir havzalarında mikroplastik taşınımı, havza hidrolojisi, toprak erozyonu ve sedimen bütçe modeli kullanılarak matematiksel olarak modellenmiştir [21]. Başka bir yaklaşımda, nehirlerden okyanuslara mikroplastiklerin girdisi, atık yönetimi, nüfus yoğunluğu ve hidrolojik bilgilere dayalı olarak tahmin edilmiştir [22]. Yapılan çalışmalar, mikroplastik konsantrasyonu ve atık yönetimi, havza özellikleri ve hidrolojik rejim arasında önemli bir ilişki olduğuna dikkat çekmiştir.

Kataoka ve arkadaşları [22]Japonya da bulunan 29 nehirden örnekler alıp mikroplastik kirliliğinin kaynaklarını araştırmışlardır. Çalışma sonucunda, mikroplastik konsantrasyonlarının önemli ölçüde kentleşme ve nüfus ile ilişkili olduğunu ayrıca, nehir sularının kalitesini gösteren biyokimyasal oksijen ihtiyacı (BOİ) parametresi ile de arasında anlamlı bir ilişki olduğunu ortaya koymuşlardır.

Nehirler, atık plastiklerin insan faaliyetlerinden kaynaklı oluşan birincil mikroplastiklerin okyanuslara girdisini sağlayan başlıca kaynaklardır [23,24]. Ayrıca nehirler, iki süreçle ikincil 
mikroplastik kaynakları haline gelir. Ek olarak, nehirler iki işlem yoluyla ikincil mikroplastik kaynakları haline gelebilir. Bir süreçlerden ilki, plastiklerin karada parçalanmasıdır. Karadaki plastik atıklar, fotooksidatif bozulma ve insan aktivitesinden kaynaklanan fiziksel hasarlar ile parçalanabilir [9] Parçalanan plastikler ise nehirlere yağmur suyu drenajı ile taşınırlar. Alternatif olarak, nehir kenarlarında veya taşkın ovalarında plastiklerin parçalanması meydana gelebilir. Karadan gelen plastik atıklar, taşkınların büyüklüğüne bağlı olarak nehir kenarlarında ve taşkın ovalarında tekrar tekrar karaya yıkandığında, plastiklerin bozunması su dışında kalma süresine bağlı olarak ilerler [9,25].

Özellikle, taşkın ovasında gelişen makrofitler, bozunma sürecine önemli ölçüde katkıda bulunacaktır. Bununla birlikte, mikroplastiklerin karadan okyanusa hareketi tam olarak anlaşılamamıştır [26].

Nehirlerdeki mikroplastiklere yönelik bilimsel kaygı hızla artmış, bu da mikroplastik konsantrasyonlarının izlenmesi [27, 28], mikroplastiklerin okyanuslara girişinin tahmin edilmesi [29,30,31], mikroplastik kirletici kaynaklarını anlama [32,33] ve tatlı su türleri üzerindeki etkileri [4,27] gibi konularda birçok mikroplastik çalışmanın yayınlanmasıyla sonuçlanmıştır.

Mikroplastiklerin su ortamlarına salınımını etkili bir şekilde önlemek için nehirlerdeki mikroplastiklerin kaynakları ve içeri akış süreçlerinin daha iyi anlaşılması gerekir. Örneğin, noktasal olmayan mikroplastik kaynaklarından gelen akış süreçleri ve bunların nokta kaynakları [32,34,35], nehir kirleticileri dikkate alınarak tartışılmalıdır.

\section{Nehirlerde Mikroplastik Taşınımı Ve Hidrodinamik Modellenmesi}

$\mathrm{Su}$ ortamında parçacıkların hareketi, advektif, dispersif ve difüze kütle transferinin sonucudur. Adveksiyon, ortalama akış hızına bağlı olarak akım yolu boyunca yatay yönde akışını belirler. Dispersif kütle transferi, kütlenin çok yoğun ortamdan az yoğun ortama türbülanslı yayılmasıdır [36]. Bu makro ölçekteki olay ideal olmayan akış yönlerinden kaynaklanır. Nehirlerde bulunan maddelerin taşınması yaygın olarak tek boyutlu Adveksiyon-dispersiyon denklemi ile tanımlanmaktadır [37]. Su ortamında taşınmanın yanı sıra, Stokes yasası veya bu yasanın bir modifikasyonu ile parçacıkların su kolonunda çökelmesi modellenebilmektedir [38]. Adveksiyon, dispersiyon, difüzyon ve çökelme olayları parçacığın boyut, yoğunluk, şekil, ve gözeneklilik gibi özelliklerinden etkilenmektedir [39].

Hidrodinamik modeller, suyun hareketine etki eden dinamik (rüzgar, akıntı, direnç katsayısı, türbülans gibi) parametreleri kullanarak, hidrodinamik veriler elde eder ve bunları mevcut bir sayısal modelleme yazılımında kullanır. Mikroplastiklerin akıbeti ve taşınması üzerindeki etkisini analiz etmek ve farklı coğrafyalarda parçacıkların adveksiyonunu ve dispersiyonunu simüle etmek için hidrodinamik modeller kullanılmaktadır. Model, advektif taşıma, partikül agregasyonu, tortulaşma, yeniden süspansiyon, polimer bozunması ve gömülmeyi hesaba katarak, mekansal ve zamansal olarak belirgin hidrodinamik partikül davranışını simüle eder. Bu modeller kullanılarak yüzey sularında mikroplastiklerin hidrodinamik birçok modeli oluşturulmuştur [40,41].

Ding ve arkadaşları tarafından parçacıklar arası ve parçacıkduvar çarpışmalarını da dikkate alan daha kapsamlı bir hidrodinamik model geliştirilmişstir [42]. Lagrange parçacık izleme yöntemiyle birleştirilmiş kafes Boltzmann yöntemini kullanarak Laizhou Körfezi çevresindeki dört farklı nehirden salınan mikroplastiklerin taşınım yollarını simüle etmeyi amaçlamışlardır. Başlangıç verileri; rüzgar, gelgit verileri, nehirlerden gelen mikroplastik parçacıkları ve su derinliğini içeriyordu. Modellenen nehirler için serbest bırakma süresi aynı olarak kabul edilmiştir. Başlangıç koşulu olarak $0 \mathrm{~ms}^{-1}$ değeri ile tüm alan üzerinde sabit rüzgar varsayılmıştır. Tüm parçacıkların yüzer olduğu ve her zaman yüzeyde yüzdüğü varsayılarak başlangıç parçacık hızının $0 \mathrm{~ms}^{-1}$ olduğu kabul edilmiştir. Parçacık çarpışmalarının değişen yörüngeler üzerinde çok az etkisi olduğu, kabul edilebilir sonuçlara rağmen, sürekli yüzen parçacıklar varsayımı, parçacığın aşağı ve yukarı gitmesine neden olabilecek hidrodinamik olayları göz ardı edilmesine sebep olmuştur. Ayrıca sürekli yüzer olduğu varsayımı ile biyofilm, çökelme ve agregasyon prosesleri ile partikül yoğunluğununun değişmediği kabulunu yapmaya itmektedir. Ayrıca, parçacıklar gerçekte aynı boyuta sahip olmayacaktır. Dalgalar ve akımlar parçacıkların kaderini, taşınmasını ve dolayısıyla birikimini de etkileyecektir. Yapılan kabuller ve varsayımlar, parçacıkların heterojenliğini yok saydığından daha sınırlı nehirlerde kullanımı uygundur.

Quik ve ekibi [43] tarafindan genel olarak nanoparçacıklara odaklanan, Hollanda Dommel Nehri çalışma alanı seçilerek bir model geliştirmişlerdir. Bu çalışmaları, mikroplastiklerle ilgili diğer modeller için öncü bir çalışma olmuştur. Model, yerel akış koşulları ile homo- ve hetero-agregasyon, yeniden süspansiyon ve sedimantasyon gibi nanopartiküllerin akım süreçleri arasındaki geri bildirimlere dayanmaktadır. Sonuçlar, mekansal heterojenliğin ihmal edilmesinin nanopartikül tutunumunda küçük farklılıklara sebep olduğunu göstermiştir. En göze çarpan sonuçlardan biri, su sütunundaki nanopartiküllerin konsantrasyonunun ve formunun, nehir akış dinamiklerinin bir sonucu olarak hızlı değişimlere maruz kalması olarak rapor edilmiştir.

Model bulguları, nanopartikül hareketlerinin değerlendirilmesinde su kolonu dinamiklerindeki değişkenliğinde dikkate alınması gerektiğini öne sürmüştür. Nanopartiküllerin homo- ve hetero-agregasyonunun mekansal değişimi hesaba katmayan, genellikle kararlı hal olan kütle-denge ve birinci mertebe modellerinden farklı olarak; sonuçlar, başlangıç değeri ile mevcut modelin çıktısı arasında önemli orantısızlıklar olduğunu ortaya koymuşlardır. $\mathrm{Bu}$ nedenlerle, bu çalışma nanopartiküllerin akış modellemesinde öncü bir çalışma olarak kabul edilebilir.

Quik ve arkadaşlarından iki yıl sonra aynı nehir için Besseling ve arkadaşları [4], mekansal-zamansal olarak çözümlenmiş bir hidrolojik model olan NanoDUFLOW modelini kullanarak tatl su sistemlerinde nano, mikro ve milimetre boyutlu küresel ve küresele yakın plastik parçacıkların akıbetini ve taşınım süreçlerini araştırmışlardır. Yazarlar, homo- ve heteroagregasyonunun, biyofilm, Stokes çökelme hızı teorisine dayalı sedimantasyon hızı, yukarı akış konsantrasyonu ve sabit yükleme, bozunma, yeniden süspanse olma ve çözünmeyi temel süreçler olarak değerlendirmişlerdir. Model sonuçları, plastik parçacıkların bir kısmının nehirde tutulabileceğini göstermiş ve bu sonuç ile nehirlerde bulunan mikroplastiklerin tamamının deniz ortamına aktarılmadığını ortaya koymuştur. Bu çalışma, parametrelerin çoğunu içeren ve mikroplastiklerin nehirlerde taşınımı ile ilgili süreçleri dikkate alan ve gelecekteki çalışmalara 1şık tutan çok kapsamlı bir çalışma olmasından dolayı oldukça önemlidir. Çalışmanın daha çok debisi düşük olan nehirlerde çalışılmış olması, plastik parçacıkların karışmasından kaynaklanan etkileşimlerin ihmal edilmesi, plastik parçacıklar 
için sadece küresel veya küresele yakın şekillerin olduğu kabulunun yapılmış olması ve bu nedenle agregasyon ve çökelme gibi bazı parçacık davranışlarının kabul edilmesi sebebiyle geliştirilmesi gerektiği görülmüştür.

\section{Sonuçlar}

Modelleme sayesinde kirlilik kaynakları ve kirleticilerin izledikleri yollar daha kolay tanımlanabilmektedir. Böylece su kaynaklarını korumak amaçlı herhangi bir noktadaki kontaminasyonu hesaplamak suretiyle kirliliği azaltma stratejileri belirlenebilmektedir.

Günümüzde denizlerimiz başta olmak üzere tüm yüzey suyu kaynaklarımızın mikroplastik kirleticiler tarafından kirletilmiş olması endişe vericidir. Bu derleme makale ile, denizlere karadan mikroplastik taşınımında en önemli kaynak olan nehirlerin mikroplastik kirliliğinin azaltılması ve uygun stratejilerin geliştirilmesinde yardımcı olacak olan hidrodinamik modeller hakkında genel bilgi verilmesi amaçlanmıştır.

Hidrodinamik modellerin; hidrodinamik olayların neden olduğu mikroplastiklerin kaderinin tahmininde, okyanus/deniz olayları açısından gerçek hayat ile uyumluluğu, yerel veya küresel ölçekte kullanılabilirliği, sediment taşınımı modeli ile bağlanma imkanlarından dolayı kullanımında güçlü yanları mevcuttur.

Modellenecek bir malzeme olarak mikroplastiklerin hidrodinamik modellenmesinde, boyutlarının, şekillerinin ve yoğunluklarının değişkenliği göz önüne alındığında benzersiz olduğu ortaya konulmuştur. Mikroplastiklerin agregalaşması/parçalanması, üzerinde biyofilm oluşumu gibi süreçler ile de parçacığın modellemede hidrodinamiğini ve boyut dağılımını etkilediği ortaya konulmuştur.

$\mathrm{Bu}$ derlemede, modelleme ile mikroplastik kirleticiler hakkındaki veri kıtlığı göz önüne alındığında nehirlerde uygun bir risk değerlendirmesini yapmak ve kirliliğin akıbeti hakkında önceden senaryolar oluşturabilmek için faydalı araçlar olduğunu vurgulamak amaçlanmıştır. Nehirler başta olmak üzere tatlı sularda mikroplastik taşınım modellemesi üzerine daha fazla araştırma ve model çalışılarak, literatüre 1 şı tutacak veri tabanı oluşturulmalıdır.

\section{Kaynaklar}

[1] Jambeck, J.R., Geyer, R., Wilcox, C., Siegler, T.R., Perryman, M., Andrady, A.,Narayan, R., Law, K.L., 2015. Plastic waste inputs from land into the ocean.Science 347, 768e771.

[2] Andrady, A.L., (2011). Microplastics in the marine environment. Marine pollution bulletin, 62(8): 1596-1605.

[3] Besseling E, Quik JTK, Koelmans AA (2014) Modeling the fate of nano- and microplastics in freshwater systems. SETAC Annual Meeting, Basel, Switzerland.

[4] Besseling E, Quik JTK, Sun M, Koelmans AA (2017) Fate of nano- and microplastic in freshwater systems: a modeling study. Environ Pollut 220:540-548

[5] Nizzetto L, Bussi G, Futter MN et al (2016) A theoretical assessment of microplastic transport in river catchments and their retention by soils and river sediments. Environ Sci Process Impacts 18:1050-1059

[6] Thompson RC, Olsen Y, Mitchell RP, Davis A, Rowland SJ, John AWG, McGonigle D, Russell AE (2004) Lost at sea: where is all the plastic Science 304(5672):838-838.

[7] Erni-Cassola, G., Gibson, M. I., Thompson, R. C., ChristieOleza, J. A. (2017). Lost, but found with Nile red: a novel method for detecting and quantifying small microplastics (1 $\mathrm{mm}$ to $20 \mu \mathrm{m}$ ) in environmental samples. Environmental science \& technology, 51(23), 13641-13648.

[8] Van Cauwenberghe, L., Devriese, L., Galgani, F., Robbens J., Janssen, C.R., 2015. Microplastics in sediments: A review of techniques, occurrence and effects, Marine Environmental Research 111, 5-17

[9] Andrady AL (2011) Microplastics in the marine environment. Mar Pollut Bull 62:1596-1605.

[10] Fendall LS, Sewell MA (2009) Contributing to marine pollution by washing your face:microplastics in facial cleansers. Mar Pollut Bull 58:1225-1228.

[11] Abbasi, S., Keshavarzi, B., Moore, F., Delshab, H., Soltani, N., \& Sorooshian, A., 2017, Investigation of microrubbers, microplastics and heavy metals in street dust: a study in Bushehr city, Iran, Environmental Earth Sciences, 76(23), 798.

[12] Browne, M. A., Crump, P., Niven, S. J., Teuten, E., Tonkin, A., Galloway, T., \& Thompson, R., 2011, Accumulation of microplastic on shorelines woldwide: sources and sinks, Environmental Science \& Technology, 45(21), 9175-917

[13] Lattin, G. L., Moore, C. J., Zellers, A. F., Moore, S. L., \& Weisberg, S. B., 2004, A comparison of neustonic plastic and zooplankton at different depths near the southern California shore, Marine Pollution Bulletin, 49(4), 291-294.

[14] Rummel, C. D., Jahnke, A., Gorokhova, E., Kühnel, D., \& Schmitt-Jansen, M., 2017, Impacts of biofilm formation on the fate and potential effects of microplastic in the aquatic environment, Environmental Science \& Technology Letters, 4(7), 258-267.

[15] Wu, W. M., Yang, J., \& Criddle, C. (2017). Microplastics pollution and reduction strategies.Frontiers of Environmental Science \& Engineering, 11(1), 6.

[16] GESAMP (The Joint Group of Experts on the Scientific Aspects of Marine Environmental Protection), 2016. Sources, Fate and Effects of Microplastics In The Marine Environment: Part Two of A Global Assessment, International Maritime Organization, Reports and Studies No 93, $221 \mathrm{p}$

[17] Akarsu, C., Kıdeyş, A.E., Kumbur, H., (2017). Evsel atık su aritma tesislerinin sucul ekosisteme mikroplastik tehditi, Türk Hijyen ve Deneysel Biyoloji Dergisi, 74(EK-1), 73-78.

[18] Mani T, Hauk A, Walter U, Burkhardt-Holm P (2015) Microplastics profile along the Rhine river. Sci Rep 5:17988

[19] Yonkos, L. T., Friedel, E. A., Perez-Reyes, A. C., Ghosal, S., \& Arthur, C. D., (2014), Microplastics in four estuarine rivers in the Chesapeake Bay, USA, Environmental Science \& Technology, 48(24), 14195-14202.

[20] Nizzetto L, Bussi G, Futter MN et al (2016) A theoretical assessment of microplastic transport in river catchments and their retention by soils and river sediments. Environ Sci Process Impacts 18:1050-1059

[21] Lebreton, L. C., Van der Zwet, J., Damsteeg, J. W., Slat, B., Andrady, A., \& Reisser, J., 2017, River plastic emissions to the world's oceans, Nature Communications, 8, 15611.

[22] Kataoka T., Nihei Y., Kudou K., Hinata H.2019. Assessment of the sources and inflow processes of microplastics in the river environments of Japan. Environmental Pollution, 244.

[23] Carr, S.A., Liu, J., Tesoro, A.G., 2016. Transport and fate of microplastic particles in wastewater treatment plants. Water. Res. 91, 174-182.

[24] Jambeck J, Geyer R, Wilcox C, Siegler TR, Perryman M, Andrady A, Narayan R, Law KL (2015) Plastic waste inputs from land into the ocean. Science 347:768-771 
[25] Kershaw, P.J., Rochman, C.M., 2016. Sources, fate and effects of microplastics in the marine environment: part 2 of a global assessment. Rep. Stud. 93, 221.

[26] Eerkes-Medrano, D., Thompson, R.C., Aldridge, D.C., 2015. Microplastics in freshwater systems: a review of the emerging threats, identification of knowledge gaps and prioritisation of research needs. Water Res. 75, 63-82.

[27] Dris R, Imhof H, Sanchez W et al (2015) Beyond the ocean: contamination of freshwater ecosystems with (micro-)plastic particles. Environ Chem 12(5):539-550

[28] Verster, C., Minnaar, K. and Bouwman, H. (2017), Marine and freshwater microplastic research in South Africa. Integr Environ Assess Manag, 13: 533-535.

[29] Lebreton LCM et al (2017) River plastic emissions to the world's oceans. Nat Commun 8:15611

[30] Nizzetto L, Langaas S, Futter M (2016) Pollution: do microplastics spill on to farm soils? Nature 537(7621):488

[31] Schmidt, C., Krauth, T., Wagner, S., 2017. Export of plastic debris by rivers into the sea. Environ. Sci. Technol. 51, 12246-12253.

[32] Carr, S.A., Liu, J., Tesoro, A.G., 2016. Transport and fate of microplastic particles in wastewater treatment plants. Water Res. 91, 174-182.

[33] Murphy, F., Ewins, C., Carbonnier, F., Quinn, B., 2016. Wastewater treatment Works (WwTW) as a source of microplastics in the aquatic environment. Environ. Sci. Technol. 50, 5800e5808.

[34] Leslie, H.A., van Velzen, M.J.M., Vethaak, A.D., 2013. Microplastic Survey of the Dutch Environment: Novel Data Set of Microplastics in North Sea Sediments, Treated Wastewater Effluents and Marine Biota. Institute for Environmental Studies, VU University Amsterdam, Amsterdam.

[35] McCormick, A., Hoellein, T.J., Mason, S.A., Schluep, J., Kelly, J.J., 2014. Microplastic is an abundant and distinct microbial habitat in an urban river, 48, 11863-11871.

[36] Ji Z-G (2008) Hydrodynamics and water quality: modeling rivers, lakes, and estuaries. Wiley, Hoboken

[37] Ani E-C, Wallis S, Kraslawski A, Agachi PS (2009) Development, calibration and evaluation of two mathematical models for pollutant transport in a small river. Environ Model Softw 24:1139-1152

[38] Kowalski N, Reichardt AM, Waniek JJ (2016) Sinking rates of microplastics and potential implications of their alteration by physical, biological, and chemical factors. Mar

Pollut Bull 109(1):310-319

[39] Khatmullina L, Isachenko I (2016) Settling velocity of microplastic particles of regular shapes. Mar Pollut Bull 114(2):871-880

[40] Sterl, M. F., Delandmeter, P., \& van Sebille, E. (2020). Influence of barotropic tidal currents on transport and accumulation of floating microplastics in the global open ocean. Journal of Geophysical Research: Oceans, 125

[41]DoblerD. , T. Huck, C. Maes, N. Grima, B. Blanke, E. Marti nez, F. Ardhuin Large impact of Stokes drift on the fate of surface floating debris in the South Indian Basin Mar. Pollut. Bull., 148 (2019), pp. 202-209

[42] Ding Y., H. Liu, W. Yang Numerical prediction of the short-term trajectory of microplastic particles in Laizhou Bay Water, 11 (2019), Article e2251.

[43] Quik J.T.K., J.J.M. de Klein, A.A. Koelmans Spatially explicit fate modelling of nanomaterials in natural waters Water Res., 80 (2015), pp. 200-208, 